\title{
The decline of HCV and HBV infection prevalence among haemodialysis patients in Southern Saudi Arabia: a success story.
}

\author{
Mohamed Elbagir K Ahmed $^{1 *}$, Haider A Omer ${ }^{1}$, Ibrahim Jubran², Suliman M Al-Humayed ${ }^{1}$, Husaam \\ H. $\mathrm{Ali}^{2}$ \\ ${ }^{1}$ Department of Medicine, College of Medicine, King Khalid University, Abha, Saudi Arabia \\ ${ }^{2}$ Department of Medicine and Nephrology, Aseer Central Hospital, Abha, Saudi Arabia
}

\begin{abstract}
Introduction and objective: Chronic hepatitis $\mathrm{C}$ and $\mathrm{B}$ impose a significant mortality and morbidity burden worldwide and particularly in the Kingdom of Saudi Arabia (KSA). In haemodialysis patients (HD) patients, chronic hepatitis, especially HCV infection poses a real problem. The objective of this communication was to assess $\mathrm{HCV}$ and $\mathrm{HBV}$ infection rates in patients undergoing haemodialysis in Abha, Southern Saudi Arabia.

Methods: In this cross-sectional hospital based study, we studied the demographic factors and the frequencies of $\mathrm{HCV}$ and $\mathrm{HBV}$ infection among all patients undergoing haemodialysis for end stage kidney disease in 2016. Those rates were compared to previous published reports.

Results: There were 200 males and 118 females with ESRD undergoing haemodialysis. The prevalence of $\mathrm{HCV}$ infection was $10 \%$ among men and $18.6 \%$ among women (was $45 \%-68 \%$ in the year 2000 ). On the other hand, one male patient $(0.5 \%)$ and 3 females $(2.5 \%)$ were infected by both HCV and HBV. HBV infection was $5 \%-11 \%$ in the year 2000.

Conclusion: The present study demonstrated a clear decline of both hepatitis $C$ and $B$ infection prevalence in a large haemodialysis facility as compared to a previous high infection rates a decade earlier. This decline is a result of strict application of the international guidelines and possible HBV vaccination programs.
\end{abstract}

Keywords: Haemodialysis, Hepatitis, Saudi Arabia.

Accepted on November 5, 2018

\section{Introduction}

Chronic hepatitis $\mathrm{B}$ and $\mathrm{C}$ impose a significant mortality and morbidity burden worldwide, particularly in the Kingdom of Saudi Arabia (KSA) [1,2].

The prevalence of hepatitis $\mathrm{C}$ virus (HCV) infection worldwide is about $3 \%$ and the infected people are estimated at 170 million. However, the prevalence rates in Africa, America, Europe and South-East Asia are under 2.5\%. Moreover, in the Western Pacific regions, the prevalence ranges between $2.5 \%$ and $4.9 \%$, while in some parts of the Middle East and the rest of the world the prevalence of $\mathrm{HCV}$ ranges between $13 \%$ and $15.7 \%[2-5]$.

Earlier than 1990, the main routes of HCV transmission were blood product transfusions, intravenous drug use, and unsafe medical procedures, especially dental ones. Since the start of the systematic screening of blood products, the risk of HCV infection related to transfusions has declined to an extremely low prevalence of 1:20000000 [6].
However, in KSA, despite the extensive measures implemented to decrease the prevalence of hepatitis, it still causes significant morbidity and mortality and creates a great burden on the resources of the ministry of health $[1,7]$.

Concerning HD patients, chronic hepatitis, especially HCV infection prevalence, has a wide range in different countries of the world varying from $1 \%$ to $90 \%$. For example, in Northern Europe the prevalence rate is less than $5 \%$ while in southern Europe and the United States it is estimated as $10 \%$. Moreover, the prevalence in several countries of Northern Africa, Asia, and South America ranges between 10\%-70\% [8].

Patients undergoing $\mathrm{HD}$ are infected with $\mathrm{HCV}$ via contaminated dialysis machines and possibly contaminated utensils. Investigating the role of dialysis machines in spreading disease, it was concluded that HD machines were the most likely source of transmission of $\mathrm{HCV}$ infection; therefore it was important to assign specific HD machines for anti-HCVpositive cases [3]. Soyannwo et al. also confirmed that machine isolation policies, rather than blood transfusions, lead to wide-spread variation in HCV prevalence among different dialysis centers in Saudi Arabia [9]. Therefore, patient isolation 
represents a secondary important factor in controlling transmission of viral hepatitis in HD units [10-12].

Furthermore, controlling the spread of hepatitis B virus (HBV) infection in dialysis units has been one of the major successes in the management of ESRD especially for the patients awaiting transplant. Unfortunately, HBV incidence and prevalence rates remain high in dialysis patients in both the developing and the developed countries, so much so that the $\mathrm{CDC}$ issued recommendations to reduce its spread within haemodialysis units $[2,13]$.

The objective of this communication was to assess the frequency of $\mathrm{HBV}$ and $\mathrm{HCV}$ infection rates in patients undergoing haemodialysis in a large dialysis unit in Abha, Southern Saudi Arabia.

\section{Methods}

This cross-sectional retrospective study was performed in 2016 among patients with end stage kidney diseases undergoing haemodialysis in a large haemodialysis center in Abha city, Southern Saudi Arabia. The charts of all male and female patients were reviewed. The demographic factors, duration of haemodialysis, HBV and HCV markers, liver function tests, and treatments, were recorded.

Hepatitis C antibodies and HBsAg, as well as PCR for viral load were analysed in the central reference laboratory of the ministry of health using a $4^{\text {th }}$ generation ELISA, (Dia Pro Diagnostic Biobrpbes, Milano, Italy).

Simple descriptive statistics (mean, SD, and $\chi^{2}$ ) were performed for data analysis using SPSS version 15.

\section{Results}

We studied all the 318 patients with ESRD undergoing haemodialysis in the main dialysis center in Abha (200 males and 118 females). The mean age of men was 41.8 y (SD 14.3) while that of women was 52.2 y (SD 16.5). The duration of haemodialysis and that of hepatitis infection are shown in Table 1. Out of the 200 men, 20 had HCV infection (10\%), and one patient was infected by both $\mathrm{HCV}$ and $\mathrm{HBV}(0.5 \%)$. Regarding the 118 women, 22 (18.6\%) were infected with HCV while $3(2.5 \%)$ were infected with both HCV and HBV. However, there is no significant difference between the infection rates in men and women. (Chi square P: 0.385, Table 2). It is interesting that none of the patients was infected with $\mathrm{HBV}$ alone. In addition to haemodialysis, added risks of hepatitis transmission were identified in 6 patients. Out of those, three were post-transplant while another three received multiple blood transfusions prior to haemodialysis.

Among the study population, we found that there is a decline of $\mathrm{HCV}$ infection prevalence among haemodialysis patients from $45 \%-68 \%$ in the year 2000 , to $18 \%-20 \%$ in the present study. Likewise, HBV infection prevalence has also declined from $5 \%-11 \%$ in the year 200 to $0.5 \%-2.5 \%$ in the present study.
Only ten patients with significantly high viral load received standard HCV treatment (Interferon and ribavirin) and were under follow up in the hepatology clinic. At that time, the new $\mathrm{HCV}$ directing acting drugs were not available at the time of the study.

Table 1. Demographic and duration information in 318 patients.

\begin{tabular}{llll}
\hline Parameter & All & Men & Women \\
\hline Total no of patients & 318 & 200 & 118 \\
\hline Mean age (SD) & $47.00(15.4)$ & $41.8(14.3)$ & $52.2(16.5)$ \\
\hline Mean duration of haemodialysis & $9.4(5.9)$ & $8.9(6.3)$ & $9.9(5.5)$ \\
\hline Duration of HCV infection (y, SD) & $7.5(4.5)$ & $7.9(5.7)$ & $7.2(3.3)$ \\
\hline
\end{tabular}

Table 2. Prevalence of $H B V$ and $H C V$ infection in the present study.

\begin{tabular}{lll}
\hline & Men (N\%) & Women (N\%) \\
\hline Type of hepatitis (N0, SD) All & & \\
\hline HCV $42(14.3 \%)$ & $20 / 200(10 \%)$ & $22 / 118(18.6 \%)$ \\
\hline HBV alone none & None & None \\
\hline HCV and HBV co-infection 4 (1.5\%) & $1(0.5 \%)$ & $3(2.5)$ \\
\hline
\end{tabular}

\section{Discussion}

The present study demonstrated lower prevalence of both hepatitis $\mathrm{B}$ and $\mathrm{C}$ infection rates as compared to previous reports from Saudi Arabia and rest of the world in this large Saudi haemodialysis facility. Several previous studies more than a decade ago have demonstrated high rates of hepatitis $\mathrm{C}$ virus infection varying from $15 \%$ to over $40 \%[3,9,10,14]$. The low prevalence rates shown in the present study are most likely a result of several factors. These include the application of stringent measures of infection control; the use of isolated dialysis machines for patients infected with hepatitis $\mathrm{B}$ and $\mathrm{C}$ viruses, and of course, the successful vaccination policy against HBV which was adopted in Saudi Arabia for the last 20 y [10-12].

In general, any decline in the infectivity with hepatitis viruses will save patients from serious complications of these infections. Other factors that have been associated with a more rapid progression of liver disease in the HD population include alcohol abuse, tobacco consumption, older age of HCV acquisition, duration of infection, as well as co-infection with HIV or other hepatotropic viruses $[15,16]$. However, there is no universal agreement regarding the role of genotype (especially 1b), viral load, metabolic syndrome, and AST levels as risk factors for progression of HCV-related liver disease. On the other hand, male gender and liver siderosis, which are established risk factors for hepatitis progression in $\mathrm{HCV}$ infected non-uremic patients, did not correlate with a more severe liver disease in HD patients $[8,16,17]$.

Although the present study demonstrated noticeable decline of both hepatitis $\mathrm{B}$ and $\mathrm{C}$ infection rates in this large 
haemodialysis facility in Saudi Arabia, HBV within dialysis units continues to spread in the industrialized world to the extent that the CDC in USA issued recommendations to reduce such spread within Hemodialysis units [13]. These guidelines included segregation of $\mathrm{HBs} \mathrm{Ag}$-positive patients by room, dialysis machines, and staff. Moreover, the guidelines also advised routine serological screening for $\mathrm{HBsAg}$ and anti-HBs antibody among such patients. Implementation of these recommendations reduced the incidence of $\mathrm{HBsAg}$ seropositivity in dialysis units in the United States from $3 \%$ to $0.5 \%$ for patients and from $2.6 \%$ to $0.5 \%$ for staff [3]. In Saudi Arabia, the implementation of such measures, including the wide adoption of vaccination, has also resulted in impressive decline of HBV infection in haemodialysis units $[1,14]$. Furthermore, the universally recommended measures such as the routine of washing hands after touching blood and other potentially infectious material, wearing gloves, gowns, and face masks, when in contact with blood, body fluids, and other potentially highly infective material, have positively contributed to such low prevalence rates of both HBV and HCV infections $[9,18]$.

In conclusion, the strict implementation of infection control measures, as well as vaccination, has led to an impressive decline of HBV and HCV infection among haemodialysis patients in Saudi Arabia. Thus, such infection control measures should be strictly adapted to further decrease the prevalence of HBV and HCV infections not only among hemodialysis units, but in any high dependency unit that cares for vulnerable or immunocompromised patients.

\section{Competing Interest}

There is no competing interest or funding to declare. Also, since patients were not involved physically or by intervention, ethical approval was not obtained.

\section{References}

1. Abdo AA, Sanai FM, Al-Faleh FZ. Epidemiology of viral hepatitis in Saudi Arabia: are we off the hook? Saudi J Gastroenterol 2012; 18: 349-357.

2. Shepard CW, Finelli L, Alter MJ. Global epidemiology of hepatitis $C$ virus infection. Lancet Infect Dis 2005; 5: 558-565.

3. Kidney Disease: Improving Global Outcomes (KDIGO) KDIGO clinical practice guidelines for the prevention, diagnosis, evaluation, and treatment of hepatitis $\mathrm{C}$ in chronic kidney disease. Kidney Int Suppl 2008; 109: 1-99.

4. Global surveillance and control of hepatitis C. Report of a WHO Consultation organized in collaboration with the Viral Hepatitis Prevention Board, Antwerp, Belgium. J Viral Hepat 1999; 6: 35-47.

5. Mosconi G, Campieri C, Miniero R, Colì L, Orsi C, La Manna G, De Sanctis LB, Stefoni S, Sprovieri G, Bonomini V. Epidemiology of hepatitis $\mathrm{C}$ in a population of hemodialysis patients. Nephron 1992; 61: 298-299.
6. Jadoul M, Cornu C, Van Ypersele de Strihou C. Non-A, non-B hepatitis in dialysis patients: diagnosis, prevention and treatment. International Yearbook of Nephrology London: Springer-Verlag 1992; 253-270.

7. Saudi Arabia Ministry of Health, Ministry of Health of Saudi Arabia (MOH). A review of health situation. Annual Health Statistics Book 2012.

8. Abu-Aisha H, Mitwalli A, Huraib SO, Al-Wakeel J, Abid J, Yousif KI. The effect of chemical and heat disinfection of the hemodialysis machines on the spread of hepatitis $\mathrm{C}$ virus infection: A prospective study. Saudi J Kidney Dis Transpl 1995; 6: 174-178.

9. Soyannwo MA, Khan N, Kommajosyula S, Abdel Rahman AR, Khadaji M, Sing R, Laithy SU, Ladha A, Azzam A, Desmukh S. Hepatitis C antibodies in haemodialysis and pattern of end-stage renal failure in Gassim, Saudi Arabia. Afr J Med Med Sci 1996; 25: 13-22.

10. Saxena AK, Panhotra BR, Sundaram DS, Naguib M, Venkateshappa CK, Uzzaman W. Impact of dedicated space, dialysis equipment, and nursing staff on the transmission of hepatitis $\mathrm{C}$ virus in a hemodialysis unit of the middle east. Am J Infect Control 2003; 31: 26-33.

11. Al-Jiffri AM, Fadag RB, Ghabrah TM, Ibrahim A. Hepatitis $\mathrm{C}$ virus infection among patients on hemodialysis in Jeddah: a single center experience. Saudi J Kidney Dis Transpl 2003; 14: 84-89.

12. Karkar A, Abdelrahman M, Ghacha R, Malik TQ. Prevention of viral transmission in HD units: the value of isolation. Saudi J Kidney Dis Transpl 2006; 17: 183-188.

13. CDC Control measures for hepatitis B in dialysis centers. Viral hepatitis investigations and control series, Atlanta. Centers for Disease Control and Prevention 2016.

14. Al-Faleh FZ, Al-Jeffri M, Ramia S, Al-Rashed R, Arif M, Rezeig M, Al-Toraif I, Bakhsh M, Mishkkhas A, Makki O, Al-Freihi H, Mirdad S, AlJuma A, Yasin T, AlSwailem A, Ayoola A. Seroepidemiology of hepatitis B virus infection in Saudi children 8 years after a mass hepatitis B vaccination programme. J Infect 1999; 38: 167-170.

15. Sakellariou S, Boletis JN, Sypsa V, Psichogiou M, Tiniakos D, Delladetsima I. Histological features of chronic hepatitis $\mathrm{C}$ in haemodialysis patients. Liver Int 2014; 34: 56-61.

16. Becker VR, Badiani RG, Lemos LB, Perez RM, MedinaPestana JO, Lanzoni VP, Ferreira AP, Silva AE, Ferraz ML. Factors associated with the progression of hepatic fibrosis in end-stage kidney disease patients with hepatitis $\mathrm{C}$ virus infection. Eur J Gastroenterol Hepatol 2009; 21: 1395-1399.

17. Espinosa M, Martin-Malo A, Alvarez de Lara MA, Aljama P. Risk of death and liver cirrhosis in anti-HCVpositive long-term haemodialysis patients. Nephrol Dial Transplant 2001; 16: 1669-1674.

18. Covic A, Abramowicz D, Bruchfeld A, Leroux-Roels G, Samuel D, van Biesen W, Zoccali C, Zoulim F, Vanholder 
R. Endorsement of the kidney disease improving global outcomes (KDIGO) hepatitis C guidelines: a European Renal Best Practice (ERBP) position statement. Nephrol Dial Transplant 2009; 24: 719-727.

\section{*Correspondence to}

Mohamed Elbagir K Ahmed

Department of Medicine

College of Medicine

King Khalid University

Saudi Arabia 